ENSAIOS / ESSAYS

\title{
AUTORIDADE E PODER: OS PROCESSOS E AS PRÁTICAS NAS ORGANIZAÇÕES HOSPITALARES
}

\section{RESUMO}

Sob a perspectiva do ambiente de mudanças e dos fatores que conduzem a gestão administrativa a um processo de contínuo melhoramento, exigindo maiores esforços do capital humano, este ensaio tem por objetivo analisar a relação da autoridade e do poder nos processos e nas práticas em organizações hospitalares. A metodologia contempla uma consistente pesquisa bibliográfica acerca do tema, mediante estudo sistematizado, utilizando-se de materiais já publicados por diversos autores, entre clássicos e contemporâneos, que versam sobre o assunto. Os principais resultados do estudo permitem concluir que, em uma organização hospitalar, o processo e a prática em relação à autoridade e poder dividem-se em determinados pontos, em virtude da atividade fim da instituição e das prioridades estabelecidas para os serviços prestados. A atenção e os cuidados médicos caracterizam a missão do hospital. A prestação de serviço altamente especializada e profissionalizada, desenvolvida pelo corpo médico, condiciona-os a uma autonomia que coloca esses cuidados e atenção em situação de prioridade à característica econômica do hospital, criando dificuldades na condução administrativa da instituição.

Palavras-chave: Gestão Hospitalar. Autoridade e Poder. Processos e Práticas Organizacionais.

\section{INTRODUÇÃO}

Diante do ambiente contemporâneo, a temática acerca das mudanças e transformações do segmento organizacional da sociedade e do trabalho tem-se tornado central na literatura, nas diversas disciplinas e em debate acadêmico e empresarial, tendo por

Roberto Rodney Ferreira

Junior rrodney508@gmail.com Doutorando em Administração de Negócios - ESEADE Argentina; Mestre em Gestão pela UTAD - Portugal; Diretor de Desenvolvimento Acadêmico do Hospital Universitário Clemente de Faria - Montes Claros - MG - BR. agente causador dessas mudanças e transformações a evolução em face do processo da globalização, da tecnologia, da pós-revolução industrial e, mais recentemente, da revolução da tecnologia da informação, sendo considerada como a era da informação.

Outras literaturas imputam às mudanças não só a esses fatores, mas também a insistente hegemonia capitalista em busca de lucratividades maiores e em detrimento do fator trabalho. Entretanto, é claramente percebido que a competitividade vem-se acentuando de maneira rigorosamente intrínseca ao contexto organiza- 
cional, buscando alcançar maior fortalecimento e, consequentemente, a consecução dos objetivos com eficiência e sucesso.

Tais fatores conduzem a gestão administrativa a um processo de contínuo melhoramento e as metas empresariais sempre a um passo a mais, exigindo-se, da mesma forma, maiores esforços do capital humano nas empresas. Essa consideração é ratificada por Giddens (1991) que, além de afirmá-la, institui três características que fundamentam a ruptura entre o velho e o novo e que apartam o moderno do tradicional. São elas: o ritmo da mudança; o objetivo da mudança e a natureza intrínseca das instituições modernas.

Por conseguinte, não se poderia deixar às margens das considerações o reconhecimento de que os sistemas de saúde também, influenciados pela modernidade, tenham passado por efetivas mudanças em suas diversas formas e graus de intensidade.

Entretanto, no segmento hospitalar, algumas características o diferenciam do modelo tradicional de empresa, principalmente pela existência de setores que se operacionalizam por procedimentos clínicos que não dependem exclusivamente da capacidade administrativa, mas da profissionalidade médico-hospitalar de tratar doenças e objetivar saúde do ser humano.

Em sentido mais amplo, essas mudanças nos sistemas de saúde podem ser verificadas por via de alterações significativas em seus indicadores, conforme registro da Who (1999), tais como: declínio da taxa de mortalidade infantil, ampliação da expectativa de vida, declínio dos índices de natalidade e transição epidemiológica evidenciada pelas alterações na mortalidade proporcional em todas as regiões.

Com base nessas verificações de mudanças, ressalta-se também o aumento da produtividade com novas tecnologias e, principalmente, o reconhecimento de que as empresas foram impelidas a uma competitividade extrema. Nesse caso em que a competitividade tornou-se acirrada entre as organizações, bem como entre as entidades hospitalares, que a modernização levou ao atendimento nos contornos empresariais, a qualidade administrativa passou a ser referência, e os programas de qualidade, essenciais.

É fato que, em qualquer organização, os recursos de produção (capital, terra, trabalho e tecnologia) têm papel determinante. No entanto, não se pode deixar de considerar que o fator trabalho, representado pelos indivíduos colaboradores, atualmente, seja o setor essencialmente importante para que a missão e os objetivos empresariais sejam alcançados. Todavia, não se pode conceber que um trabalhador mal orientado, insatisfeito, não motivado com a própria função, consiga alcançar resultados para a empresa de forma satisfatória (para ambos), conforme afirma Medeiros (2007), ao argumentar que não parece ser possível desenvolver um trabalho, qualquer que seja ele, sem uma mistura de racionalidade e emoção.

Para tanto, torna-se necessário que o líder utilize a razão e a sensibilidade e tenha capacidade de visão futura e de acompanhamento das mudanças em sua volta. Mesmo porque, o diferencial do líder, consiste na equipe motivada, interessada e inspirada. O tempo mudou, e a motivação imposta pelo poder perdeu espaço para a parceria e para o relacionamento humanizado, capaz de produzir motivação.

Nesse aspecto, este ensaio objetiva analisar, à luz da literatura, a relação da autoridade e do poder nos processos e nas práticas das organizações hospitalares.

Justificou-se o presente estudo pela relevância em se buscar entender as dificuldades que os gestores encontram quanto às práticas e aos processos nas organizações hospitalares, notadamente na implantação/implementação e manutenção de equipes de alto rendimento em busca de uma gestão mais qualificada, profissionalizada e, consequentemente, de organizações mais sólidas.

\section{BREVE ABORDAGEM SOBRE A ADMINISTRAÇÃO}

Mediante as considerações neoclássicas e ao fato de que a Administração não é senão o ato de administrar, e diz respeito a um determi- 
nado ramo de atividade que se realiza a partir do comando de outro e por meio de pessoas, considera-se que a administração seja um instrumento meio. Um instrumento essencial em toda e qualquer cooperação organizada, em todos os níveis da organização, dirigindo os negócios e gerindo bens, com pretensões de se alcançar os objetivos organizacionais (KOONTZ; O'DONNELL, 1982; CHIAVENATO, 2001; MARINHO, 2005; TENÓRIO, 2005).

Reportando-se à Administração como ciência, área em que se circunscrevem as funções administrativas, tem-se que esse fenômeno "administração", segundo Drucker (1972), é considerado como sendo a máxima, a principal chave para a solução dos mais graves problemas que afligem o mundo moderno. Em outra exposição de mesmo sentido, Koontz e O'Donnell $(1982$, p. 4) afirmam que é por intermédio do administrador "que se determina a diferença entre uma organização bem-sucedida e uma destinada a fracassar".

Não obstante, o termo administração tem sido mantido ao longo do tempo, enquanto que o seu significado, no mundo organizacional, vem passando por transformação radical desde a sua acepção original. Nessa condição, principalmente, tomando-se a abstração, sob o ponto de vista neoclássico, tem-se que a administração significa:

[...] interpretar os objetivos propostos pela organização e transformá-los em ação organizacional por meio do planejamento, organização, direção e controle de todos os esforços realizados em todas as áreas e em todos os níveis da organização, a fim de alcançar tais objetivos de maneira eficiente e eficaz. (CHIAVENATO, 2001, p. 9).

Considerando, então, os aspectos gerais da administração, pode-se inferir, segundo ponto de vista de Marinho (2005), três ações importantes na condução de uma instituição empresarial, que são: administrar como processo, administrar como sistema e gerir.
Para o autor, administrar como processo significa planejar, dirigir, organizar, coordenar e controlar organizações e/ou tarefas, tendo como objetivo maior a produtividade e/ou a lucratividade [...] administrar como sistema ou atividade dinâmica, consiste em tomar decisões sobre objetivos e recursos [...] a gestão passou a significar de forma mais comum à interferência direta dos gestores nos sistemas e procedimentos empresariais. (MARINHO, 2005, p. 3).

Desse modo, pode-se reafirmar que a Administração de Empresas consta como disciplina pragmática, direcionada para resultados e, por conseguinte, deve-se entendê-la como uma eterna busca de objetivos com eficácia e eficiência, aplicando o conhecimento à ação e humanização às relações interpessoais entre liderança e subordinados, motivando e otimizando resultados (DRUCKER, 1972; CAMPOS, 1994; CHIAVENATO, 2001).

Reportando-se ao fundamento administrativo principal, a Teoria Geral da Administração, com vistas para a Teoria Neoclássica, não deixa de ser o ajuste e a adaptação da Teoria Clássica ao mundo organizacional moderno, cujo resultado é ponto de relevância.

Assim, nessa visão, segundo Chiavenato (1999), as relações no interior das organizações tomaram novo rumo: a empresa desprezou a administração de pessoas para operar em uma nova visão de administração com pessoas.

\section{PROCESSOS E PRÁTICAS ORGANI- ZACIONAIS EM ORGANIZAÇÕES HOSPITALARES}

Em sentido amplo, na modernidade e em função dela, tem-se percebido que as organizações em todos os âmbitos: Estado, trabalho, escola, família e outros mais, estão em constante crise, principalmente, por não se saber prever como estará o mundo adiante.

Santos (1995) afirma que se vive uma era da informação e da globalização, cujos eventos 
se transmitem em tempo real, o que significa estar submetido a uma cultura determinada e de domínio que impõe mudanças contínuas nas relações sociais, com apontamento para a pós-modernidade. Portanto, é razoável enfatizar que os gestores de estabelecimentos hospitalares são os responsáveis por sua eficiência, bem como pela qualidade da prestação dos serviços ali disponibilizados, ou o seu contrário.

Precedendo a abordagem, é bom salientar que, em uma organização hospitalar, a gestão se delineia em duas áreas distintas: a administrativa que, assumindo o papel empresarial, atua de forma equivalente a outra empresa qualquer, e a de serviços clínico/médicos, que são funções básicas da atividade hospitalar.

Para o primeiro caso (administrativo), necessariamente, é de se convir que o desenvolvimento econômico em um hospital, como em outra empresa mercantil, vem impondo uma cultura de gestão empresarial, por meio de paradigmas inovadores, voltados para a capacitação administrativa e gerencial, objetivando o atendimento a uma competitividade crescente dos mercados, o que não ocorre apenas nos segmentos produtivos de transformação e comercialização, mas também nas prestações de serviços (DIAMANTE, 2003).

Os clientes que passaram a ser exigentes na opção de escolha de produtos de qualidade estão tornando-se, também, cada vez mais críticos em relação a serviços prestados, criando, por conseguinte, maiores impressões e expectativas em relação aos serviços obtidos.

Entretanto, é fato, e deve ser considerado, que nas gestões hospitalares é comum a ocorrência de falhas, uma vez que profissionais de saúde que assumem a direção ou a administração de uma entidade hospitalar estão capacitados à realização de procedimentos relacionados à sua formação e, na maioria das vezes, não foram treinados ou ensinados a conquistar e manter clientes nem gerenciar organizações com foco na lucratividade (NOGUEIRA, 1993).

Reportando-se às questões organizacionais, ressalta-se, segundo Bernardes (1993, p.
17) que a organização, conceitualmente, é compreendida como:

[...] uma associação de pessoas que têm a função de produzir bens, prestar serviços à sociedade e atender necessidades de seus próprios participantes. Deve a organização possuir uma estrutura formada por pessoas que se relacionam, colaborando e dividindo o trabalho para transformar insumos em bens e serviços; ser perene no tempo. (BERNARDES, 1993, p. 17).

A partir desse entendimento, pode-se argumentar que as organizações, de um modo geral, surgem com uma missão, uma estrutura, um modelo funcional, com recursos apropriados para a obtenção do serviço e, consequentemente, combinam entre si alguns métodos organizacionais. Vale também assinalar que, em relação aos modelos estruturais das organizações, dois formatos se apresentam: o da organização vertical e o da horizontal.

$\mathrm{Na}$ organização vertical, a característica é dada à forma estrutural, demarcada pela departamentalização, com presença de vários setores e vários chefes. Segundo FREITAS (2004, p. 1), é uma estrutura que dificulta o fluxo da informação entre departamentos, criando problemas de qualidade. Por outro lado, "a organização horizontal caracteriza-se por uma estruturação por processos, cujo fluxo da informação se dá de forma independente dos departamentos, fluindo melhor, uma vez que os processos são essencialmente responsáveis tanto pela qualidade dos produtos, quanto dos serviços" (POSSAMAI, 2002, p. 1).

Na visão de Drucker (1999) e de Kaplan e Norton (1997), quatro fatores relevantes passaram a influenciar os novos modelos de gerenciamento organizacional: as mudanças nos modelos de gestão, dando origem à inovação estrutural da empresa; a globalização da economia; as mudanças tecnológicas com foco nas informações e no conhecimento e, por fim, as novas formas de gestão, cuja competência e conhecimento são agregadores de valor ao co- 
laborador, otimizando a produtividade e a competitividade.

Já nas instituições prestadoras de serviços de saúde, as atividades devem ser executadas em conformidade com os preceitos da eficácia. Observando-se a relevância de se ouvir o cliente e permitir que o trabalho seja realizado efetivamente. Pois, na verdade, este cliente não é, senão, a razão da existência da organização (MARTINEZ, 2002).

Em um hospital, o objetivo principal está em proporcionar atenção aos clientes, ali inseridos como pacientes, mesmo que limitado pelos recursos humanos, econômicos e tecnológicos. Porém, como em qualquer organização, um hospital também deve possuir departamentos com profissionais especializados, realizando suas funções, mediante a colaboração de pessoal de apoio e serviços auxiliares disponíveis (DIAMANTE, 2003).

Segundo Teixeira (1983, p. 23):

O trabalho no hospital é mutuamente suplementar e interdependente, e esta situação determina que as funções especializadas e as atividades de muitos departamentos sejam suficientemente coordenadas, para que a instituição funcione eficientemente e atenda seus objetivos, permitindo continuidade nas operações organizacionais. Desta forma, o hospital necessita de um sistema muito aperfeiçoado de coordenação interna, que não pode se ater aos mecanismos padrões, em função do fluxo de trabalho muito variável e irregular que existe nessa organização. (TEIXEIRA, 1983, p. 23).

Em uma instituição hospitalar, o alvo é o paciente, o que faz que o hospital dependa de um ajuste constante, que Teixeira (1983) entende ser impossível que se detalhe pelas regras formais administrativas de uma organização, uma vez que o paciente depende efetivamente da interação pessoal de indivíduos responsáveis pelos cuidados necessários, seja o atendimento a uma consulta, uma internação, seja outro procedimento, sempre visando à falha e ao erro.

\section{O INDIVIDUO E O PROCESSO COGNITIVO}

O homem é um ser racional e social com tendência irrepreensível para a vida em sociedade. É um ser que vive e convive em organizações, em ambientes que, cada vez mais, vão-se tornando complexos e dinâmicos. Entretanto, com uma grande variabilidade humana que individualiza e caracteriza cada um, como um fenômeno multidimensional, passível a influência de inúmeras variáveis (LEAVITT DILL; EYRNG, 1973 apud PEREIRA; OLIVEIRA, 2004).

Essa variação pode ser plenamente percebida nas aptidões, nos padrões comportamentais, pela própria personalidade, na conduta e na interpretação de valores, inclusive nas motivações. Por isso mesmo, o homem, como ser humano multidimensional, tem a necessidade de ser estudado e entendido, principalmente, no que concerne à cognição humana, na qual o conceito é reservado à maneira segundo a qual o indivíduo se vê e interpreta a si mesmo ou o ambiente em que está inserido. É, portanto, um filtro individual, por meio do qual os indivíduos sentem e percebem a si e o ambiente, estabelecendo juízo pessoal (PEREIRA; OLIVEIRA, 2004).

Nesse sentido é que Festinger (1975), por meio da Teoria da dissonância cognitiva, afirma que todo indivíduo procura estabelecer um estado de consonância ou coerência com ele mesmo. Quando ocorre, a partir da opinião e do juízo, a incoerência, há um estado de dissonância cognitiva que passa a ser um dos principais elementos de inconsistência comportamental, criando um conflito denominado dissonância. Geralmente, a dissonância cognitiva se manifesta em situações de envolvimento de algum processo de decisão do indivíduo e o conflito resultante de cognições que não combinam entre si.

Thompson e Van Houten (1970 apud PEREIRA; OLIVEIRA, 2004), esclarecem que em decorrência da teoria de campo e da dissonância cognitiva, surgem três enfoques 
que direcionam o estudo do comportamento do indivíduo:

- O homem como ser transacional, que recebe insumos do meio ambiente e reage aos mesmos, mas também adota uma posição proativa, antecipando e provocando mudanças neste ambiente;

- O homem com um comportamento dirigido para um objetivo, que é capaz de ter objetivos e aspirações e se esforçar para alcançá-los;

- O homem como um modelo de sistema aberto, que é dirigido para objetivos é ativamente envolvido com o ambiente à medida que persegue estes objetivos, desenvolvendo capacidades mentais tais como: pensar, decidir, permitindo que conheça as pessoas, suas crenças e as coisas em seu ambiente e enfrentá-las (VAN HOUTEN, 1970 apud PEREIRA; OLIVEIRA, 2004, p. 7).

Tratando-se do indivíduo no ambiente de trabalho, é conveniente e justo ressaltar que as organizações dependem efetivamente das pessoas para que funcionem de maneira adequada e satisfatória, alcançando os seus objetivos, atingindo o sucesso e, consequentemente, a continuidade, que é expectativa de qualquer instituição empresarial.

Porém, a conciliação entre os interesses empresariais e os interesses individuais sempre se manifestam de forma conflitiva, chamado conflito industrial. Caracteriza-se pelo interesse, ou mesmo necessidade empresarial da eficiência de seus colaboradores para alcance da lucratividade e passam a usar métodos que exigem eficiência, sem levar em consideração a cooperação. Esse fato tem levado a estudos de equilíbrio entre os interesses dentro das organizações (PEREIRA; OLIVEIRA, 2004).

Nesse aspecto, percebe-se que, para os indivíduos se valorizarem nas organizações, faz-se necessário que sua visão se destaque como recurso de habilidade, capacidade e conhecimento na execução de suas tarefas e funções, com o intuito de alcançar os objetivos organizacionais para uma visão de pessoa (ser humano), com características próprias de personalidade, de aspirações, valores, crenças, motivação, conduta e expectativas. Nesse aspecto, rompe-se o entendimento taylorista de pessoas como: exclusivo meio de produção (DIAMANTE, 2003).

Dessa forma, constituindo-se a organização em um ambiente humanitário, ela requer uma coordenação adequada em relação à divisão de trabalho, buscando sempre a personalização do serviço em relação ao paciente e observando que, no contexto hospitalar, a questão autoridade e poder têm inferência diferenciada em razão tanto da especialidade das funções profissionais relacionadas à saúde, que representam atividade fim da instituição, quanto da necessidade de que ele seja entendido de forma especial no contexto da prestação de serviços.

\section{AUTORIDADE E PODER}

Para um melhor entendimento da questão, procurou-se buscar significado com auxílio da Língua Portuguesa, com base em Bueno (1996), sobre o que vem a ser autoridade e poder. Segundo o autor, o termo "autoridade" quer dizer "direito de se fazer obedecer; poder de mandar; prestígio; magistrado que exerce o poder; pessoa competente no assunto" (BUENO, 1996, p. 86). Quanto ao "poder", significa "ter a faculdade ou possibilidade de; ter autorização para; estar sujeito, arriscado, exposto a; ter ocasião ou oportunidade de; ter força de ânimo para; ter o direito de; ter influência, força; ter vigor ou capacidade (física ou moral) para suportar, para aguentar" (BUENO, 1996, p. 512).

No entendimento de Nogueira (2005) e Souza (2008), a autoridade é uma qualidade ou simples fonte de poder que também é considerada como fundamento em qualquer organização hierarquizada e, sobretudo, no sistema político. É por meio da autoridade que se transmite mensagem, muitas vezes, sem a necessidade de transmitir suas razões ou justificativas, deven- 
do ser atendida pelos indivíduos subordinados. O poder, por sua vez, é interpretado como o direito de liderar, de agir, de ordenar e, conforme o contexto, a faculdade de exercer a autoridade.

Nessas considerações, percebe-se que o conteúdo da autoridade ampara uma condição de superioridade e de determinação que sobrepõe ao poder, refletindo, certamente, uma situação de execução e de cumprimento de determinações.

Ressalta-se que, sendo o ambiente hospitalar modernizado, adequou-se ao estilo empresarial e, a partir de então, diante das mudanças ambientais e organizacionais, passou a implementar diferenciais na gestão de suas instituições, voltando-se para a eficiência, em virtude, principalmente, da complexidade estrutural, passando também a haver, na comunicação, razões suficientes para contribuir com as relações políticas e os segmentos estratégicos. Esse tipo de comunicação passou também a representar um mecanismo social em razão da atenção à saúde (TEIXEIRA, 1983).

Tratando-se de autoridade e poder no ambiente hospitalar, não se pode deixar de considerar que o trabalho ali exercitado deve estar integrado, salientando-se que, nesse mesmo sentido, as especialidades profissionais de saúde também necessitam interagir. Porém, nessa interação, alguns obstáculos se manifestam presentes, muitas vezes originados da própria complexidade ou das relações de poder que são construídas, mas que podem vir a interferir na gestão da instituição hospitalar.

Teixeira (1983) chegou a esclarecer que, em uma instituição hospitalar, encontram-se quatro centrais de poder: a diretoria superior, os médicos, a administração e os demais profissionais, destacando-se entre eles a enfermagem.

Esse é o diferencial administrativo dos hospitais, uma vez que, nesse tipo de instituição, a autoridade não surge de uma única dimensão de poder, não flui de uma única linha de comando, como ocorre nas demais organizações formais (NOGUEIRA, 1993).

Nas organizações formais hierarquizadas, a prática e a Teoria têm demonstrado um alinhamento estrutural, cuja diretoria delega responsabilidades gerenciais ao administrador, que, por sua vez, delega responsabilidades de comando às chefias de setores e de serviços, assim por diante (NASSER, 2008).

Para Teixeira (1983), o corpo clínico de uma instituição hospitalar pode subordinar-se ao diretor ou ao administrador. Entretanto, a natureza da sua atividade já é um fator de estabelecimento de autonomia para os médicos em seu trabalho, bem como de autoridade profissional sobre outros setores, haja vista que a atenção à saúde é prioritariamente determinante nessa instituição, o que diversifica a linha de comando. Não obstante, essa variação de linha de comando, às vezes, cria dificuldades administrativas e organizacionais (NASSER, 2008).

Nessa direção, os autores citados fazem alusão a algumas características desafiadoras que se manifestam na administração hospitalar. No atendimento hospitalar, segundo Teixeira (1983) e, diferentemente de muitas organizações formais, o serviço de atenção e tratamento sempre é personalizado e nunca padronizado ou uniforme. Mesmo porque o valor econômico agregado situa-se secundariamente ao valor social e humano e ainda, a disponibilização dos serviços vincula-se às necessidades das pessoas, realçando o fato de que essas necessidades são sempre importantes e prioritárias.

Dessa forma, para o corpo médico, em determinados casos, submeter-se a autoridade e ao poder da administração, quando a sua profissão lhe aponta a atenção e o cuidado como ponto prioritário, poderia ser um fator de dissonância, visto que, em primeiro lugar, a coerência para o médico é suplantar qualquer fator, no sentido de promover a saúde da pessoa. Por outro lado, a menor autoridade e poder sentida pelo administrador em função do exposto podem ser elemento de dificuldade para algumas decisões.

Outro fato importante é que os serviços se manifestam, muitas vezes, em situação de urgência/emergência, estabelecendo, pela importância da necessidade, responsabilidades 
diferenciadas aos atendentes, com intolerância ao erro, pois são casos de indivíduos que atendem indivíduos e, portanto, compõe de forma ativa o processo produtivo da instituição hospitalar. Segundo Teixeira (1983), nesses casos, o administrador não tem controle total sobre os colaboradores, especialmente sobre médicos e pacientes. Portanto, nas organizações hospitalares, é menor sua autoridade e poder.

Ainda, segundo o autor, um hospital, até certo ponto, é uma organização burocrática e autoritária em virtude de sua operacionalidade. No entanto, é altamente especializada, departamentalizada e profissionalizada, demonstrando sua eficácia, eficiência na efetividade do benefício social.

\section{CONSIDERAÇÕES FINAIS}

$\mathrm{Na}$ busca por analisar a relação da autoridade e do poder nos processos e práticas nas organizações hospitalares, percebem-se alguns pontos importantes e que devem ser considerados.

Primeiramente, é que os hospitais, na atualidade, passaram a exercer suas atividades de forma muito formal e conforme as demais organizações. O que ocorreu, certamente, na realidade, foi que, em um hospital, a administração também é um instrumento meio que deverá ser essencial para o planejamento, a organização, a direção e o controle da entidade, portanto, um fator chave para a solução dos problemas graves que afligem o mundo moderno.

Percebeu-se, de maneira geral, que é função do administrador da instituição hospitalar manter a eficiência, sob a égide da autoridade, em uma condição superior ao do poder, pois é por via da autoridade que se delegam poderes nas organizações hierarquizadas.

No entanto, nas práticas e nos processos exercidos nas organizações hospitalares, a autoridade, em função da autonomia e da atividade fim da entidade, elege o corpo médico/ clínico a uma independência de decisões, que o afasta, de certa forma, da autoridade administrativa, o que, de certa maneira, provoca dificuldades administrativas.
O profissional da administração, ao contrário do de saúde, está pronto para conquistar e manter cliente/paciente como um indivíduo fidelizado, enquanto o setor de saúde, também pronto em sua especialidade, está apto a manter a saúde desse cliente/paciente, estabelecendo ao aspecto econômico da entidade, uma posição secundária em relação ao aspecto social desenvolvido pelos serviços ali prestados.

Esses fatos mostram que, em um hospital, os serviços são mutuamente suplementares e interdependentes, mas que não fogem à necessidade da coordenação e organização do hospital, o que leva a entidade a uma necessidade de um aperfeiçoamento interno eficaz e contínuo, sem, no entanto, ater-se às padronizações, justamente pelo modelo variável e das complexidades ali existentes. Porém, buscando-se a integração de todos os setores, tanto administrativo quanto médico.

$\mathrm{Na}$ verdade, o que se apresenta é que os médicos e administradores dos hospitais, juntos, devem antecipar-se às mudanças nas formas de relacionamento que mantêm com contratantes de seus serviços. Devem estabelecer como objetivos a diminuição de custos e a melhoria da qualidade do atendimento prestado aos clientes, para, assim, posicionar-se favoravelmente no mercado. Os médicos, em seu trabalho, se destacam, porém a maneira como os administradores trabalham com esses profissionais pode resultar em uma vantagem competitiva. As organizações de saúde precisam dotar seus profissionais de conhecimento, oferecendo-lhes oportunidades excepcionais para que possam contribuir com a ciência médica.

\section{AUTHORITY AND POWER: THE PROCEDURES AND PRACTICES IN HOSPITAL ORGANIZATIONS}

\section{ABSTRACT}

In the perspective of environmental changes and factors that conduce hospital management to a continuous improvement process, 
requiring greater efforts of human capital, this essay aims to examine the relationship of authority and power in the processes and practices in hospitals. The methodology includes a consistent literature research on the subject, by a systematic study, using materials which have already been published by several authors, among classic and contemporary, who deal with this subject. From the main results of the study it can be concluded, that in hospitals the process and practice in relation to authority and power divide themselves at certain points, because of the core activity of the institution and the established priorities for the services provided. The attention and medical care that characterize the hospital's mission, providing highly specialized and professionalized services developed by the medical staff, might place doctors in a situation of autonomy in which they might give priority to care and attention rather than to the economic characteristics of the hospital, creating difficulties for the management of the institution.

Keywords: Hospital Management. Authority and Power. Organizational Processes and Practices.

\section{REFERÊNCIAS}

BERNARDES, Cyro. Teoria geral da administração. São Paulo: Atlas, 1993.

BUENO, Francisco da Silva. Minidicionário da língua portuguesa. São Paulo: FTD, 1996.

CAMPOS, Vicente Falconi. TQC - Gerenciamento da rotina do trabalho do dia-a-dia. Belo Horizonte: Fundação Christiano Ottoni, Escola de Engenharia da UFMG; Rio de Janeiro: Bloch, 1994.

CHIAVENATO, Idalberto. Gestão de pessoas: o novo papel dos recursos humanos nas organizações. Rio de Janeiro: Elsevier, 1999.
. Teoria geral da administração. 6. ed.

Rio de Janeiro: Campus, 2001. v. 1.

DIAMANTE, Cristina. Modelo de gestão para organizações prestadoras de serviços de saúde. 2003. 98f. Dissertação (Mestrado em Engenharia de Produção) - Universidade Federal de Santa Catarina, Florianópolis, 2003.

DRUCKER, Peter Ferdinand. Desafios gerenciais para o século XXI. Tradução de Nivaldo Montingelli Jr. São Paulo: Pioneira, 1999.

Tecnologia, gerência e sociedade. Petrópolis: Vozes, 1972.

FESTINGER, Leon. Teoria da dissonância cognitiva. Rio de Janeiro: Zahar, 1975.

FREITAS, Newton. Gestão para crescer na crise. Folha de S. Paulo, São Paulo, 31 out. 2004, Especial Carreira Executiva, p. 1.

GIDDENS, Anthony. As consequências da modernidade. São Paulo: UNESP, 1991.

KAPLAN, Robert S.; NORTON, David P. A estratégia em ação: balanced scorecard. 11. ed. Rio de Janeiro: Campus, 1997.

KOONTZ, Harold; O’DONNELL, Cyril. Princípios de administração: uma análise das funções administrativas. 11. ed. Tradução da 4. ed. americana por Paulo C. Goldschmidt e Fernando G. Carmona. São Paulo: Pioneira, 1982.

MARINHO, Raul. Administração de empresas: do know-how para o know-why. 2005. Disponível em: <http://www.administradores. com.br>. Acesso em: 13 fev. 2014.

MARTINEZ, Silvia. A administração de serviços e o cliente nas organizações de saúde e hospitalares. Revista o Mundo da Saúde, São Paulo, ano 26, n. 2, p. 217-221, abr./jun. 2002.

MEDEIROS, José Rafael de. Liderança ino- 
vadora: segredo está na diferença entre poder e autoridade. 2007. Disponível em: $<$ http://noticias.uol.com.br/economia/carreiras/ultnot/info money/2007/0>. Acesso em: 1 mar. 2014.

NASSER, Maria Rosana Ferrari. Comunicação: políticas e estratégias para área da saúde. 2008. Disponível em: <http://reposcom.portcom.intercom.org.br/dspace/bitstream/1904/17581/1/R0391-1.pdf>. Acesso em: 13.03.2014.

NOGUEIRA, Carlos. Diferença entre autoridade e poder. 2005. Disponível em: $<$ http:// www.vemconcursos.com/opiniao/index.pht$\mathrm{ml}$ ?page $\_$sub $=5 \&$ page $\mathrm{id}=1808>$. Acesso em: 21 set. 2014 .

NOGUEIRA, R. P. Conceitos e princípios para programas de gestão da qualidade em serviços de saúde. Rio de Janeiro: Qualitimark, 1993.

PEREIRA, Maurício Fernandes; OLIVEIRA César Augusto. A contribuição dos fatores motivacionais para a qualidade: o caso da Samarco Mineração S/A. In: SIMPÓSIO DE ADMINISTRAÇÃO DA PRODUÇÃO, LOGÍSTICA E OPERAÇÕES INTERNACIONAIS - SIMPOI, 7., 2004, São Paulo. Anais... São Paulo: FGV-EAESP, 2004.

POSSAMAI, O. Mensagem pessoal: notas de orientação. [mensagem pessoal]. Mensagem recebida por<diamante@onda.com.br> em 2002.

SANTOS, Boaventura de Sousa. Um discurso sobre as ciências. 7. ed. Portugal: Edições Afrontamento, 1995.

SOUZA, Carlos Luis de. Administração e liderança do tecnólogo em radiologia. Curitiba: Faculdade de Tecnologia Camões, 2008. Disponível em: <http://www.conter.gov.br/ portal/trabalhoscientificos/carlosSouza.pdf $>$. Acesso em: 12 fev. 2015.

TEIXEIRA, José Manuel de C. O hospital e a visão administrativa contemporânea. São Paulo: Pioneira, 1983.

TENÓRIO, Fernando G. (Org.) Gestão de ONG's: principais funções gerenciais. 9. ed. Rio de Janeiro: FGV, 2005.

WHO. World Health Organization. The world health report 1999: making a difference. Geneva: [s.n.], 1999. 